\title{
Quantitative assessment of the association between erector spinae muscle and in-hospital mortality in elderly patients with pulmonary tuberculosis
}

\author{
Ai Tanaka ${ }^{1,2+}$, Kosaku Komiya ${ }^{1,2^{*}+}$, Mari Yamasue ${ }^{1,2 \dagger}$, Yumiko Ando ${ }^{3}$, Yukiko Takeno ${ }^{1,2}$, Shuichi Takikawa ${ }^{1}$ \\ Kazufumi Hiramatsu ${ }^{2}$ and Jun-ichi Kadota ${ }^{2}$
}

\begin{abstract}
Objective: Skeletal muscle size is considered a predictor of prognosis in patients with respiratory diseases including Mycobacterium avium complex lung disease. However, no research focused on its impact on prognosis in patients with pulmonary tuberculosis (TB). Thus, this study aimed to assess the association between erector spinae muscle (ESM) size and in-hospital mortality among patients with pulmonary TB.

Results: We retrospectively included 258 consecutive patients aged over 65 years old, who were admitted to the hospital for bacteriologically confirmed pulmonary TB, and all underwent chest computed tomography (CT) scan upon admission. The cross-sectional area of the ESM (ESMcsa) was measured at the lower margin of the 12th thoracic vertebra on a single-slice CT scan image and was adjusted according to body surface area (BSA). In total, 71 (28\%) patients died during hospitalization. The non-survivor group had a high incidence of respiratory failure and comorbidities and lower hemoglobin and albumin levels, performance status score, and ESMcsa/BSA. Multivariate analysis revealed that low performance status score and hemoglobin and albumin levels, but not ESMcsa/BSA and body mass index, could independently predict in-hospital mortality after adjusting for age and comorbidities. Therefore, ESM size was not associated with in-hospital mortality in patients with pulmonary TB.
\end{abstract}

Keywords: Tuberculosis, Erector spine muscles, Chest CT, In-hospital death

\section{Introduction}

Tuberculosis (TB) is a major public health threat worldwide, and the coronavirus disease 2019 pandemic had a negative effect on the early and accurate detection of tuberculosis due to lockdown or restrictions in-hospital visits [1]. To control TB infection in the community and

\footnotetext{
*Correspondence: komiyakh1@oita-u.ac.jp

${ }^{\dagger}$ Ai Tanaka, Kosaku Komiya and Mari Yamasue contributed equally to this study and they are Members of the Oita Prefectural Tuberculosis Control Project 2020-2022

1 Department of Internal Medicine, National Hospital Organization NishiBeppu Hospital, 4548 Tsurumi, Beppu, Oita 874-0840, Japan

Full list of author information is available at the end of the article
}

to facilitate early detection of pulmonary TB, effective treatment strategies with anti-TB drugs and other nonpharmaceutical interventions should be established. The identification of prognostic factors can be helpful for not only rigorous prediction but also the consideration of effective interventions.

As for a prognostic factor, recent studies have shown the associations between skeletal muscle size and disease severity and prognosis in several respiratory diseases [2-8]. The erector spinae muscle (ESM) is a major muscle that plays a role in respiration in addition to maintaining an erect posture [9]. ESM size can be easily measured when pulmonary diseases are evaluated on

(c) The Author(s) 2021. This article is licensed under a Creative Commons Attribution 4.0 International License, which permits use, sharing, adaptation, distribution and reproduction in any medium or format, as long as you give appropriate credit to the original author(s) and the source, provide a link to the Creative Commons licence, and indicate if changes were made. The images or other third party material in this article are included in the article's Creative Commons licence, unless indicated otherwise in a credit line to the material. If material is not included in the article's Creative Commons licence and your intended use is not permitted by statutory regulation or exceeds the permitted use, you will need to obtain permission directly from the copyright holder. To view a copy of this licence, visit http://creativeco mmons.org/licenses/by/4.0/. The Creative Commons Public Domain Dedication waiver (http://creativecommons.org/publicdomain/ zero/1.0/) applies to the data made available in this article, unless otherwise stated in a credit line to the data. 
chest CT scan, and the quantification of this muscle may be helpful in predicting disease progression in chronic pulmonary disease (COPD) [2-5], idiopathic pulmonary fibrosis (IPF) $[6-8,10]$, and Mycobacterium avium complex (MAC) lung disease [11, 12]. However, no study has focused on its impact on prognosis in patients with pulmonary TB. Therefore, the current study aimed to assess the association between ESM size and in-hospital mortality among patients with active pulmonary $\mathrm{TB}$.

\section{Main text \\ Methods \\ Patients and study design}

This was a retrospective cohort study conducted at National Hospital Organization Nishi-Beppu Hospital, the only institution that can accept patients with smearpositive lung TB in Oita Prefecture, Japan. We included consecutive patients aged over 65 years old with bacteriologically confirmed pulmonary TB using real-time PCR for the detection of Mycobacterium tuberculosis DNA who were admitted to the hospital between January 2013 and December 2016. These patients underwent chest CT scan within 1 month before and after admission, and data on height and weight were recorded to calculate body mass index (BMI) and body surface area (BSA) for the analysis of ESM size. The number of samples was calculated using EpiTools (https://epitools.ausvet.com. $\mathrm{au} /$, two-tailed, $\alpha$ error $=0.05$ and power $=0.8)$. In total, 217 patients were required according to a previous report that evaluated the association between ESMcsa and mortality among patients with MAC [11]. The study protocol was approved by the institutional ethics committee of our institution (approval number: 2-04; approval date: June 29, 2020). The need for informed consent was waived by the committee due to the retrospective design of the study. Information regarding this research was posted at the hospital, with an opt out method. Some patients already participated in previous studies [13-17].

\section{Data collection}

Patient data-including gender, age, BMI, daily physical activity levels and underlying diseases (diabetes mellitus, cerebrovascular disease, Herat failure, COPD, chronic kidney disease, and hepatic disease), smoking history, laboratory data (white blood cell concentration, hemoglobin, serum albumin, C-reactive protein, liver enzymes, blood urea nitrogen, and creatinine), sputum information (smear grade, results of sputum culture, and time to negative conversion), and presence of respiratory failure-were obtained from medical records. Collection and examination of data are routinely performed when a patient diagnosed with lung TB is admitted to our hospital. Then, we evaluated daily physical activity upon admission using a performance status scale [18]. Respiratory failure was defined as an oxygen saturation of $90 \%$ without oxygen therapy upon admission. The primary outcome was all-cause in-hospital mortality. The patients who died in the hospital or those who survived to be discharged were classified as the nonsurvivors or survivors. These data were extracted by two respiratory physicians.

\section{Evaluation of chest CT scan findings}

A 16-detector row CT scanner (Activision, Toshiba Medical Systems, Tokyo, Japan) was used. Scans were performed using 1.0-mm thick sections of contiguous images from the apex to the lung base. Images were obtained at a window setting of $-600 \mathrm{HU}$ (level) and $1600 \mathrm{HU}$ (width). If the patient underwent $\mathrm{CT}$ scan before referral to our hospital, the CT scan features were evaluated using the images obtained at the referring institutions.

Chest CT images reconstructed using the mediastinal setting were used for the quantitative analysis of the ESM. Using the evaluation method utilized in previous studies $[5,19]$, the ESM area on cross-sectional CT scan image (ESMcsa) was measured at the lower margin of the 12th thoracic vertebra using the SYNAPSE volume analyzer (FUJIFILM Medical Co., Ltd., Tokyo, Japan). In brief, the left and right ESMs were identified and manually shaded. Moreover, the cross-sectional areas of both ESMs were calculated using NOBORI viewer (TECHMATRI, Tokyo, Japan), a medical information platform, by a respiratory medicine specialist (AT) and a radiologist (YA) who were blinded to the clinical information. The ESMcsa was presented as the sum of the right and left muscles. ESMcsa was adjusted according to BSA (calculated using height and weight).

\section{Statistical analysis}

Statistical analyses were performed using the Statistical Package for the Social Sciences software version 24 (IBM Japan, Tokyo, Japan). For two-tailed analyses, 95\% confidence intervals were calculated. Variables among patients' backgrounds, laboratory data, presence of respiratory failure, and ESMcsa/BSA with a $P$ value of $<0.05$ in the univariate analysis were included in the multivariate analysis. To explain why ESMcsa was independent of other variables when used as a predictor of mortality, Cox proportional hazards regression analysis was performed to evaluate the effect of ESMcsa/BSA on in-hospital mortality.

\section{Results}

\section{Baseline characteristics of the survivor and non-survivor} groups

In total, 262 patients were admitted to the hospital, and all underwent chest CT scan. Among them, 258 (98\%) 
whose height and weight were measured upon admission were eventually included in this study. Approximately $50 \%$ of patients were women, and the median patients' age was 84 (interquartile range: $79-88$ ) years. M. tuberculosis that is resistant to more than one first-line anti-TB drug was isolated in $15(6 \%)$ patients. However, no bacterium was resistant to combined isoniazid and rifampin. In total, 71 (28\%) patients died during hospitalization. Compared with the survivor group, the non-survivor group had a significantly lower performance status score and hemoglobin and albumin levels; higher incidence of comorbidities, such as chronic kidney diseases, heart failure, and hepatic diseases, and respiratory failure; and greater C-reactive protein (CRP) levels, as shown in Table 1. The ESM $\mathrm{CSA}_{\mathrm{BSA}} / \mathrm{BS}$ of the non-survivor group was significantly lower than that of the survivor group.

\section{Predictors of in-hospital mortality in patients} with pulmonary tuberculosis

We conducted a multivariate analysis in five models because significant differences were observed among similar variables reflecting nutritional or physical status, performance status, hemoglobin and albumin levels, and $\mathrm{ESM}_{\mathrm{CSA}} / \mathrm{BSA}$ in the univariate analysis. Results showed that performance status and hemoglobin and albumin levels, but not ESMcsa/BSA and BMI, were significantly associated with in-hospital mortality after adjusting for age, comorbidities, CRP level, and respiratory failure (Table 2).

\section{Discussion}

This study showed that ESMcsa/BSA was not significantly associated with in-hospital mortality after adjusting for

Table 1 Univariate analysis of the baseline characteristics associated with in-hospital mortality of the patients with pulmonary tuberculosis

\begin{tabular}{|c|c|c|c|c|c|}
\hline & $\begin{array}{l}\text { Non-survivor } \\
(n=71)\end{array}$ & $\begin{array}{l}\text { Survivor } \\
(n=187)\end{array}$ & $H R$ & $95 \% \mathrm{Cl}$ & P \\
\hline Female & $36(50.7)$ & $94(50.3)$ & 0.813 & $0.508-1.302$ & 0.389 \\
\hline Age (y) & 87 (81-90) & $82(78-88)$ & 1.036 & $0.997-1.077$ & 0.073 \\
\hline BMI $\left(\mathrm{kg} / \mathrm{m}^{2}\right)$ & $17.8(15.7-20.3)$ & $19.1(17.4-21.2)$ & 0.944 & $0.876-1.018$ & 0.133 \\
\hline PS & $4(3-4)$ & $2(1-3)$ & 2.441 & $1.745-3.415$ & $<0.001$ \\
\hline DM & $19(26.8)$ & $45(24.1)$ & 1.091 & $0.644-1.848$ & 0.745 \\
\hline CVD & $14(19.7)$ & $30(16.0)$ & 1.164 & $0.648-2.090$ & 0.612 \\
\hline Heart failure & $21(29.6)$ & $26(13.9)$ & 1.896 & $1.135-3.167$ & 0.014 \\
\hline COPD & $7(9.9)$ & $14(7.5)$ & 1.502 & $0.685-3.293$ & 0.310 \\
\hline CKD & $17(23.9)$ & $18(9.6)$ & 2.880 & $1.658-5.001$ & $<0.001$ \\
\hline Hepatic disease & $11(15.5)$ & $8(4.3)$ & 3.289 & $1.712-6.321$ & $<0.001$ \\
\hline Smoker & $15(21.1)$ & $32(17.1)$ & 1.416 & $0.799-2.511$ & 0.234 \\
\hline Respiratory failure & $43(60.6)$ & 39 (20.9) & 2.882 & $1.782-4.660$ & $<0.001$ \\
\hline $\mathrm{WBC}\left(\times 10^{3} / \mu \mathrm{L}\right)$ & $6.6(4.8-10.0)$ & $6.5(5.2-8.1)$ & 1.026 & $0.957-1.100$ & 0.474 \\
\hline $\operatorname{Neu}\left(\times 10^{3} / \mu \mathrm{L}\right)$ & $5.4(4.1-8.9)$ & $4.8(3.6-6.6)$ & 1.074 & $1.003-1.150$ & 0.040 \\
\hline $\mathrm{Hb}(\mathrm{g} / \mathrm{dL})$ & $10.3(9.1-11.5)$ & $11.5(10.2-12.9)$ & 0.722 & $0.631-0.827$ & $<0.001$ \\
\hline Albumin (g/dL) & $2.1(1.7-2.5)$ & $3.0(2.5-3.5)$ & 0.203 & $0.128-0.321$ & $<0.001$ \\
\hline CRP (mg/dL) & $6.6(3.4-12.2)$ & $2.6(0.8-6.4)$ & 1.057 & $1.031-1.084$ & $<0.001$ \\
\hline AST (IU/L) & $27.0(20.0-42.5)$ & $25.0(20.0-35.0)$ & 1.006 & $1.003-1.009$ & $<0.001$ \\
\hline ALT (IU/L) & $17.0(12.0-27.5)$ & $16.0(11.0-25.0)$ & 1.006 & $1.002-1.011$ & 0.004 \\
\hline BUN (mg/dL) & $26.0(17.0-37.3)$ & $16.5(12.6-21.2)$ & 1.023 & $1.011-1.034$ & $<0.001$ \\
\hline $\mathrm{Cr}(\mathrm{mg} / \mathrm{dL})$ & $0.76(0.43-1.10)$ & $0.72(0.56-0.89)$ & 1.533 & $1.203-1.954$ & 0.001 \\
\hline $\mathrm{eGFR}\left(\mathrm{mL} / \mathrm{min} / 1.73 \mathrm{~m}^{2}\right)$ & $76.2(47.7-138.7)$ & $78.4(61.6-107.1)$ & 1.001 & $0.997-1.004$ & 0.724 \\
\hline Smear Grade & $1(0-3)$ & $1(0-3)$ & 1.222 & $0.812-1.838$ & 0.337 \\
\hline Time to negative conversion (day) & $38(20-53)$ & $48(32-66)$ & 0.978 & $0.968-0.988$ & $<0.001$ \\
\hline $\operatorname{ESM}_{\mathrm{CSA}}\left(\mathrm{mm}^{2}\right)$ & $1306.2(1042.3-1624.4)$ & $1715.7(1296.2-2328.0)$ & 0.999 & $0.999-1.000$ & $<0.001$ \\
\hline $\mathrm{ESM}_{\mathrm{CSA}} / \mathrm{BSA}\left(\mathrm{mm}^{2}\right)$ & $999.7(784.8-1139.3)$ & $1290.9(975.0-1558.5)$ & 0.999 & $0.998-0.999$ & $<0.001$ \\
\hline ESM-CT number (HU) & $19.6(-3.9-35.5)$ & $28.9(8.6-40.2)$ & 0.995 & $0.986-1.003$ & 0.226 \\
\hline
\end{tabular}

Data are presented as the number (\%) or median (interquartile range)

BMI: body mass index; PS: performance status; DM: diabetes mellitus; CVD: cerebrovascular disease; COPD: chronic obstructive pulmonary disease; CKD: chronic kidney disease; ESM $_{\mathrm{CSA}}$ : the cross-sectional area of erector spinae muscles; BSA: body surface area 


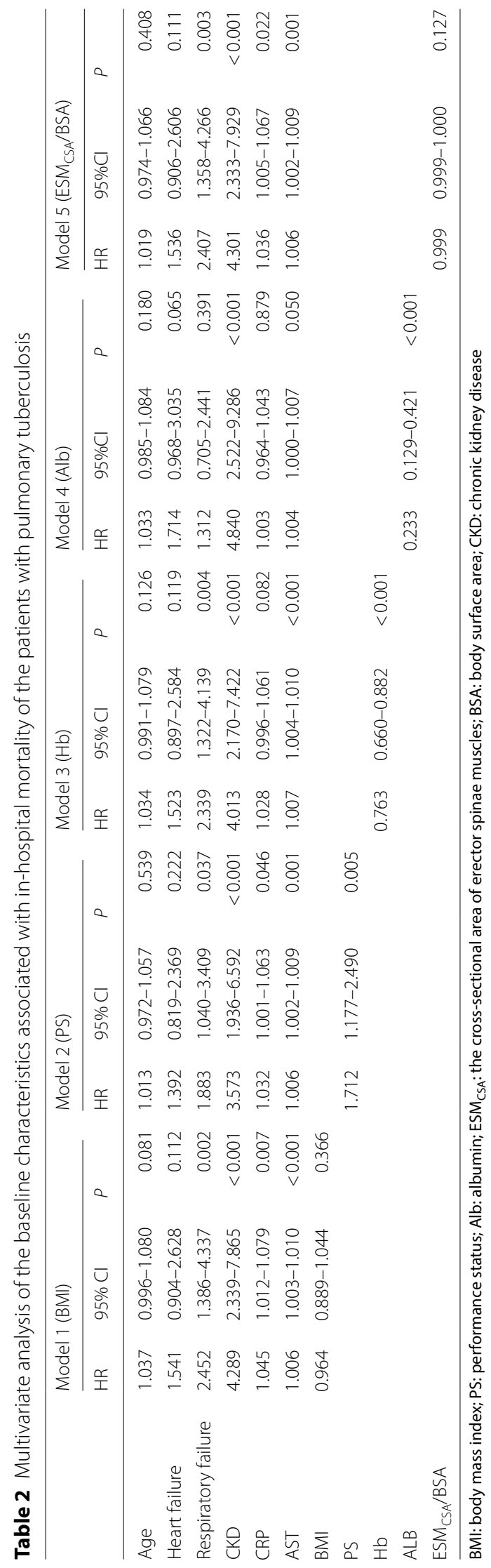


age, comorbidities, CRP level, and respiratory failure in patients with active pulmonary TB. In contrast, physical activity level assessed based on performance status and hemoglobin and albumin levels were significantly correlated with mortality. This result is consistent with that of previous studies showing that these factors play a significant role in predicting poor prognosis [14, 20,21].

TB and non-TB Mycobacterium are bacteriologically under the same category as acid fast bacterium. However, ESM size could be a predictor of mortality in patients with MAC, but not in those with TB [11]. Several possible reasons can be considered. First, the patterns of disease progression differ between TB and MAC. While $\mathrm{MAC}$ is a chronic and slowly progressive infectious disease, TB is an acute or subacute progressive disease [22, 23]. Chronic progressive disease may decrease physical activities and affect nutritional status. Hence, these factors could influence disease progression, and vice versa. Indeed, skeletal muscle size was found to be associated with chronic respiratory diseases such as COPD and IPF $[2,3,6,10]$. Second, effective antibacterial treatments could affect differences in impact of skeletal muscle size on mortality between TB and MAC. Patients with pulmonary TB are treated with multiple anti-TB drugs, and this condition is highly treatable. However, standard regimens including rifampicin, ethambutol, and clarithromycin can be effective in $50 \%$ of patients with MAC 1 year after sputum conversion [24]. If there are no effective treatment regimens for MAC, host factors such as muscle size are considered more influential on disease prognosis. Third, in this study, the primary outcome was in-hospital mortality. However, studies on MAC focused on lifetime mortality [11]. Long-term physical activity level or nutritional status generally declines; thus, lifetime mortality might be affected by these variables. If TB patients are followed-up after treatment completion, results may show that muscle size influences lifetime mortality. Finally, the overall ESMcsa/BSA was lower in the current research than in previous studies $[5,6,11]$ probably because super-aged patients significantly accounted for the sample in this study. In Japan, newly diagnosed TB is commonly observed in elderly patients. Hence, this population might cause small variations in ESMcsa/BSA in this study.

\section{Limitation}

The current study had several strengths. That is, it first assessed the relationship between ESMcsa/BSA and mortality in patients with $\mathrm{TB}$, and all consecutive patients underwent chest CT scan. Japan is one of the countries in which physicians commonly perform chest CT scan daily. We routinely perform chest CT scan on patients with pulmonary $\mathrm{TB}$ to evaluate the features of this condition in detail and to rule out malignancies. However, the study also had several limitations. First, as this was a single-centered retrospective study that included a large population of elderly patients, the results are not generalizable to younger populations in other countries. However, since several countries can face aging and the aging society in the near future, these findings will be useful. Second, the primary outcome in this study was all-cause in-hospital mortality, and TB-related mortality was not distinguished from non-TB-related mortality. Whether death was associated with TB or non-TB causes is challenging to determine in clinical practice. Third, elderly patients find it difficult to maintain spine posture during chest $\mathrm{CT}$ scan, and this may cause measurement bias. Finally, as the ESM is a respiratory muscle, respiratory function should be investigated to evaluate its correlation with ESM/BSA. However, respiratory functional tests are not conducted from a perspective of infection control in hospitals.

In conclusion, ESM size was not associated with inhospital mortality, whereas performance status and hemoglobin and albumin levels after adjusting for age, comorbidities, CRP level, and respiratory failure in patients with pulmonary TB. Thus, the quantification of ESM size might not be useful in predicting at least shortterm prognosisin patients with pulmonary TB.

\section{Abbreviations \\ ESM: Erector spinae muscle; CT: Computed tomography; ESMcsa: Cross-sec- tional area of the ESM; BSA: Body surface area; TB: Tuberculosis; COPD: Chronic pulmonary disease; IPF: Idiopathic pulmonary fibrosis; MAC: Mycobacterium avium complex; BMI: Body mass index.}

\section{Acknowledgements}

The authors thank Mr. Hideyuki Kato, Dr. Hiroshi Kawano, Dr. Tatsuya Otsu, Dr. Masahide Hara, and Dr. Kazuya Goto (National Hospital Organization Nishibeppu Hospital, Oita) for their advice and support.

\section{Authors' contributions}

AT, KK, MY, YT and JK designed this study and drafted the manuscript. AT, $\mathrm{KK}, \mathrm{MY}, \mathrm{YA}, \mathrm{ST}, \mathrm{KH}$, and JK contributed to the data collection, data analysis, and helped draft the manuscript. All authors read and approved the final manuscript.

\section{Funding}

This research did not receive any specific grant from funding agencies in the public, commercial, or not-for-profit sectors.

\section{Availability of data and materials}

All data generated or analysed during this study are included in this published article and its supplementary information files.

\section{Declarations}

Ethics approval and consent to participate

The study protocol was approved by the Institutional Ethics Committee of National Hospital Organization Nishi-Beppu Hospital, Oita, Japan (Approval Number: 2-04; Approval Date: 29 June 2020). The need for informed consent was waived by the committee due to the retrospective design of the study. 


\section{Consent for publication \\ Not applicable.}

\section{Competing interests}

All authors have stated explicitly that there are no conflicts of interest in connection with this article.

\section{Author details}

1 Department of Internal Medicine, National Hospital Organization NishiBeppu Hospital, 4548 Tsurumi, Beppu, Oita 874-0840, Japan. ${ }^{2}$ Department of Respiratory Medicine and Infectious Diseases, Oita University Faculty of Medicine, 1-1 Idaigaoka, Hasama-machi, Yufu, Oita 879-5593, Japan.

${ }^{3}$ Department of Radiology, National Hospital Organization Nishi-Beppu Hospital, 4548 Tsurumi, , Beppu, Oita 874-0840, Japan.

Received: 30 November 2020 Accepted: 26 March 2021 Published online: 13 April 2021

\section{References}

1. Komiya K, Yamasue M, Takahashi O, Hiramatsu K, Kadota Jl, Kato S. The COVID-19 pandemic and the true incidence of Tuberculosis in Japan. J Infect. 2020:81(3):e24-5.

2. McDonald ML, Diaz AA, Ross JC, San Jose Estepar R, Zhou L, Regan EA, Eckbo E, Muralidhar N, Come CE, Cho MH, et al. Quantitative computed tomography measures of pectoralis muscle area and disease severity in chronic obstructive pulmonary disease. A cross-sectional study. Ann Am Thorac Soc. 2014;11(3):326-34.

3. Diaz AA, Martinez $\mathrm{CH}$, Harmouche R, Young TP, McDonald ML, Ross JC, Han ML, Bowler R, Make B, Regan EA, et al. Pectoralis muscle area and mortality in smokers without airflow obstruction. Respir Res. 2018;19(1):62.

4. Bak SH, Kwon SO, Han SS, Kim WJ. Computed tomography-derived area and density of pectoralis muscle associated disease severity and longitudinal changes in chronic obstructive pulmonary disease: a case control study. Respir Res. 2019:20(1):226.

5. Tanimura K, Sato S, Fuseya Y, Hasegawa K, Uemasu K, Sato A, Oguma T, Hirai T, Mishima M, Muro S. Quantitative assessment of Erector Spinae muscles in patients with chronic obstructive pulmonary disease. Novel chest computed tomography-derived index for prognosis. Ann Am Thorac Soc. 2016;13(3):334-41.

6. Suzuki Y, Yoshimura K, Enomoto Y, Yasui H, Hozumi H, Karayama M, Furuhashi K, Enomoto N, Fujisawa T, Nakamura Y, et al. Distinct profile and prognostic impact of body composition changes in idiopathic pulmonary fibrosis and idiopathic pleuroparenchymal fibroelastosis. Sci Rep. 2018;8(1):14074

7. Awano N, Inomata M, Kuse N, Tone M, Yoshimura H, Jo T, Takada K, Sugimoto C, Tanaka T, Sumikawa H, et al. Quantitative computed tomography measures of skeletal muscle mass in patients with idiopathic pulmonary fibrosis according to a multidisciplinary discussion diagnosis: a retrospective nationwide study in Japan. Respir Investig. 2020;58(2):91-101.

8. Moon SW, Choi JS, Lee SH, Jung KS, Jung JY, Kang YA, Park MS, Kim YS, Chang J, Kim SY. Thoracic skeletal muscle quantification: low muscle mass is related with worse prognosis in idiopathic pulmonary fibrosis patients. Respir Res. 2019;20(1):35.

9. O'Connell DG, Brewer JF, Man TH, Weldon JS, Hinman MR. The effects of forced exhalation and inhalation, grunting, and Valsalva Maneuver on forehand force in collegiate tennis players. J Streng Condit Res. 2016;30(2):430-7.

10. Sheth JS, Xia M, Murray S, Martinez CH, Meldrum CA, Belloli EA, Salisbury $\mathrm{ML}$, White ES, Holtze CH, Flaherty KR. Frailty and geriatric conditions in older patients with idiopathic pulmonary fibrosis. Respir Med. 2019;148:6-12.

11. Asakura T, Yamada Y, Suzuki S, Namkoong H, Okamori S, Kusumoto T, Niijima Y, Ozaki A, Hashimoto M, Yagi K, et al. Quantitative assessment of erector spinae muscles in patients with Mycobacterium avium complex lung disease. Respir Med. 2018;145:66-72.

12. Akahori D, Suzuki Y, Yokomura K, Shirai M, Yasui H, Hozumi H, Karayama M, Furuhashi K, Enomoto N, Fujisawa T, et al. Body composition changes successfully classify prognosis in patients with Mycobacterium avium complex lung disease. J Infect. 2019;79(4):341-8.

13. Goto A, Komiya K, Kan T, Honjo K, Uchida S, Takikawa S, Yoshimatsu T, Fujimoto K, Johkoh T, Kadota JI. Factors associated with atypical radiological findings of pulmonary tuberculosis. PLoS ONE. 2019;14(7):e0220346.

14. Honjo K, Komiya K, Kan T, Uchida S, Goto A, Takikawa S, Yoshimatsu T, Wong ZSY, Takahashi O, Kadota J. The impact of performance status on tuberculosis-related death among elderly patients with lung tuberculosis: a competing risk regression analysis. J Infect Chemother. 2020;26(1):69-75

15. Kan T, Komiya K, Honjo K, Uchida S, Goto A, Kawano H, Takikawa S, Yoshimatsu T, Kadota JI. Impact of additional antibiotics on in-hospital mortality in tuberculosis isolated general bacteria: a propensity score analysis. J Infect Chemother. 2019;25(9):714-9.

16. Komiya K, Goto A, Kan T, Honjo K, Uchida S, Takikawa S, Yoshimatsu T, Hiramatsu K, Kadota Jl. A high C-reactive protein level and poor performance status are associated with delayed sputum conversion in elderly patients with pulmonary tuberculosis in Japan. Clin Respir J. 2020;14(3):291-8.

17. Matsumoto H, Komiya K, Yamasue M, Shuto H, Goto A, Kan T, Honjo K, Uchida S, Takikawa S, Yoshimatsu T, et al. Features of active pulmonary tuberculosis without abnormal chest $X$-ray findings. Infect Dis. 2020;52(7):520-3.

18. Oken MM, Creech RH, Tormey DC, Horton J, Davis TE, McFadden ET, Carbone PP. Toxicity and response criteria of the Eastern Cooperative Oncology Group. Am J Clin Oncol. 1982;5(6):649-55.

19. Lee CS, Cron DC, Terjimanian MN, Canvasser LD, Mazurek AA, Vonfoerster E, Tishberg LM, Underwood PW, Chang ET, Wang SC, et al. Dorsal muscle group area and surgical outcomes in liver transplantation. Clin Transpl. 2014;28(10):1092-8

20. Uchida S, Komiya K, Honjo K, Umeki K, Nureki SI, Takikawa S, Ando M, Hiramatsu K, Kadota Jl. A mini systematic review of prognostic factors in elderly patients with tuberculosis. Respir Investig. 2019;57(3):207-12.

21. Hameed S, Zuberi FF, Hussain S, Ali SK. Risk factors for mortality among inpatients with smear positive pulmonary tuberculosis. Pak J Med Sci. 2019;35(5):1361-5.

22. Hwang JA, Kim S, Jo KW, Shim TS. Natural history of Mycobacterium avium complex lung disease in untreated patients with stable course. Eur Respir J. 2017;49(3):1600537.

23. Kimizuka Y, Hoshino Y, Nishimura T, Asami T, Sakakibara Y, Morimoto K, Maeda S, Nakata N, Abe T, Uno S, et al. Retrospective evaluation of natural course in mild cases of Mycobacterium avium complex pulmonary disease. PLoS ONE. 2019;14(4):e0216034.

24. Kwak N, Park J, Kim E, Lee CH, Han SK, Yim JJ. Treatment outcomes of Mycobacterium avium complex lung disease: a systematic review and meta-analysis. Clin Infect Dis. 2017;65(7):1077-84.

\section{Publisher's Note}

Springer Nature remains neutral with regard to jurisdictional claims in published maps and institutional affiliations. 